\title{
Attention Deficit/Hyperactivity Disorder and
} Associated Factors Among Children Attending Pediatric Outpatient Departments of West Shewa Zone Public Hospitals, Central Ethiopia

Misael Benti

Adamu Birhanu Bayeta

Haji Abu (iD

Department of psychiatry Nursing, College of Medicine and Health Sciences Ambo University, Ambo, Ethiopia
Correspondence: Misael Benti Ambo University, P.O.Box:19, Ambo, Ethiopia

Tel +251938035486

Email misaelbenti@gmail.com
Background: Attention deficit/hyperactivity disorder is a common childhood-onset neurodevelopmental disorder that affects the child's psychosocial, educational, neuropsychological functioning self-esteem and quality of life from childhood to adulthood. It is estimated to affect about $5 \%$ of children and a third leading cause of disabilities.

Objective: To assess the prevalence of attention deficit/hyperactivity disorder and its associated factors among children attending pediatric OPD in hospitals found in West Shoa zone, Central Ethiopia, 2020

Methods: Institution-based cross-sectional study was conducted from January 2020 to February 2020 among 422 children attending pediatric OPD in selected hospitals in West Shewa Zone and disruptive behavioral rating scale was used to collect data. OPD (out patient department) is section of hospital where patients who receive treatment without staying overnight are seen. Data were entered into Epi info version 7.1.2 and exported to SPSS version 21 for analysis. Descriptive statistics were done. Bivariate logistic regression was done to examine the relationship between different independent variables with attention deficit/hyperactivity disorder. Variable with p-value $<0.05$ was taken as statistically significant.

Results: The prevalence rate of attention deficit/hyperactivity disorder (ADHD) among children attending pediatric $\mathrm{OPD}$ was $8.4 \%, 95 \% \mathrm{CI}(5.9,11.1)$. Being male $(\mathrm{AOR}=3.35,95 \% \mathrm{CI}(1.52$, 7.38), age 6-11 ( $\mathrm{AOR}=3.38 \mathrm{CI}(1.22,9.39))$, having a family size greater than five ( $\mathrm{AOR}=3.95, \mathrm{CI}$ $(1.44,10.11))$, low family income $(\mathrm{AOR}=3.47,95 \% \mathrm{CI}(1.25,10.10)$, presence of one or more psychosocial stressors $(\mathrm{AOR}=4.50,95 \% \mathrm{CI}(1.77,9.42))$, family history of mental illness $(\mathrm{AOR}=$ $3.6,95 \% \mathrm{CI}(1.78,8.21))$ and mothers having complication during pregnancy $(\mathrm{AOR}=3.05, \mathrm{CI}$ $(1.10,8.48))$ were factors found to be associated with ADHD.

Conclusion: Prevalence of attention deficit/hyperactivity disorder in this study is higher than global prevalence. This study has shown us ADHD is a public health issue that requires great emphasis and it is found to be associated with being male, younger age, large family size, low family income, psychosocial stressors, family history of mental illness and complication of pregnancy are factors associated with ADHD.

Keywords: Ambo, prevalence, associated factors

\section{Background}

Attention deficit/hyperactivity disorder (ADHD) is a common childhood-onset neurodevelopmental disorder that affects the child's psychosocial, educational, and neuropsychological functioning, self-esteem, and quality of life from childhood 
to adulthood. ${ }^{1}$ It affects preschoolers, children, adolescents, and adults. ADHD is characterized by a pattern of diminished sustained attention, and increased impulsivity or hyperactivity. ADHD has three subtypes: predominantly inattentive presentation, predominantly hyperactive/impulsive presentation, and combined presentation. According to diagnostic and statistical manual text revision 5 (DSM 5), several inattentive or hyperactive-impulsive symptoms were present before age 12 years and result in the failure of the child's performance at school, home, work and a decline in the social, individual, or educational performance. $^{2-4}$

There is a high rate of co-morbidities among children affected by ADHD. Learning disorder, which accounts for $47 \%$ of co-morbidity, is the most prevalent followed by conduct disorder (28\%) and opposition defiant disorder which is $22 \%$. There is also a high rate of depression (547\%) among children with ADHD. ${ }^{5}$ Evidence suggests children with ADHD have high risk of having substance use disorder like cigarette smoking when compared with none ADHD children. ${ }^{6}$

\section{Statement of the Problem}

Attention deficit hyperactivity disorder (ADHD) is the most prevalent neuropsychiatric disorder in childhood and adolescence Worldwide. According to a metaanalysis done by Polanczyk et al, the global pooled prevalence rate of ADHD is estimated to be $5.29 \%$ in children and adolescents aged 18 years or younger. ${ }^{7}$

ADHD impacts the life affected children in many aspects. Several studies demonstrated that ADHD extremely impacts the lives of individuals in association with a high cost of treatments and with affecting the entire aspects of life. One of the most important areas affected is educational performance, as it affects individuals' attention, concentration and memory. According to the 2006 report of the US Department of Education, about 30\% of children affected by ADHD have a learning disorder. They experience dyslexia, inability of doing basic calculations and difficulty with written communication. ${ }^{8-12}$

Attention deficit/hyperactivity disorder affects the social life as well. Aggressive behavior can be manifested by children with ADHD, particularly those with predominantly hyperactive-impulsive subtype which in turn can lead to frequent fighting. Those affected by predominantly inattentive subtypes of ADHD may also be more withdrawn. Children with the inattentive subtype of ADHD are woefully passive so they may remain unrecognized and often remain unassisted. In addition, children with ADHD are unable to control their own behavior which results in self-isolation, rejection by peers and consequently has poor self-esteem. ${ }^{13,18}$

As well as impacting the lives of the affected children, ADHD also affects the life of families of children with ADHD or carers. It is highly associated with a huge burden on carers. ${ }^{14}$ A study done in Douche revealed that parents of children with ADHD have a 75\% higher probability of divorce 10 years after childbirth and have less labor supply when compared with non ADHD parents. ${ }^{15}$

In addition, ADHD places a substantial economic burden on patients, families, and third party payers. A review of literature by Luis S Matza has shown that the cost of care for an adult with ADHD ranges from \$ 4929 to \$ 5651 annually. Another review of published articles done by Pelham, Foster, and Robb on thirteen studies has estimated that the average cost of illness (COI) for ADHD treatment and other healthcare to be $\$ 2636$ per year, with a range from $\$ 790$ to $\$ 5518$. $^{8}$

Another incredible study conducted on the impact of ADHD was a study conducted across 6 European countries (France, Germany, Italy, the Netherlands, Spain, and the United Kingdom), using the Lifetime Impairment Survey (LIS) among535 parents/caregivers of children with ADHD and 424 parents/caregivers of children without ADHD. According to this study, $60 \%$ of parents/care giver reported that ADHD had grossly affected their child's self-esteem, and about $70 \%$ reported that their child would be able to have more success if they were free of ADHD. ${ }^{14}$

Early and accurate diagnosis of ADHD, treatment, care, and support improve the life of patients with ADHD. Treatment alleviates the patients' stress and worry and reduces the care giving burden of parents and brings remarkable changes to their quality of life. ${ }^{2,14}$ The value of early diagnosing and treatments are also illustrated well in the review of Simone Vibert (2018), and described it as life-changing. Simple things such as being able to concentrate on work, or even just organizing the house, often became much easier for those who were able to access medication, therapy, or both. ${ }^{17,27}$ Chacko et al 2014 illustrated the latest treatment approach. It has shown that combined neurocognitive plus skill-based interventions in the context of adult-mediated supportive instruction and behavioral skills practice will improve the neurocognitive function in children with ADHD. ${ }^{16}$ 
In African countries, there is no adequate data regarding intervention and outcome of ADHD. Despite high prevalence and morbidity of disease the burden of ADHD is not extensively studied in developing countries. Particularly in Ethiopia, as to my knowledge, there are only two published studies regarding the prevalence of ADHD. Majority of children with ADHD remain undiagnosed and not receive any appropriate specialized care. Therefore, this study aims to identify the magnitude of ADHD and its associated factors in West Shewa Zone.

\section{Objective}

\section{General Objective}

- To assess the prevalence of ADHD and associated factors among children attending pediatric OPD in hospitals found in West Shoa zone, Central Ethiopia, 2019.

\section{Specific Objective}

1. To determine the prevalence of ADHD among children attending pediatric OPD in hospitals found in West Shoa Zone, Central Ethiopia, 2019.

2. To identify factors associated with prevalence among children attending pediatric OPD of hospitals found in West Shoa Zone, Central Ethiopia, 2019.

\section{Methods and Materials}

The institution-based cross sectional study was conducted in west Shewa Zone, Oromia regional state, Central Ethiopia. Four hospitals namely, Gindeberet Hospital, Ambo General Hospital, and Bako hospitals were randomly selected and data were collected from January to February, 2020. Four hundred and twenty-two participants whose age ranges from 6 to 15 years were selected using the systematic sampling technique. Informed Consent was collected from the Parents/guardian before the data collection. The presence of attention deficit hyperactivity disorder was assessed using the Disruptive Behavior Disorder rating scale (DBD rating scale). The DBD rating scale is a proxy-administered (parent or teacher) questionnaire that is based on the Diagnostic and Statistical Manual of Mental Disorders, 4th Edition (DSM-IV) diagnostic criteria for attention deficit hyperactivity disorder (ADHD). It has subscales for the inattention, hyperactivity-impulsivity, and 2 behavioral neurology combined subtypes. We used only 18 items out of 45 items of the DBD rating scale.
Each symptom was rated on a 4-point scale indicating the occurrence and the severity of symptoms: 1 (not at all), 2 (just a little), 3 (pretty much), or 4 (very much). The symptom was accepted as positive when the respondent rates it as pretty much. To say the study subject has inattention, six or more symptoms of inattention are needed to be rated as pretty much. Similarly, the study subject is considered as having hyperactivity-impulsive subtype of ADHD, if he/ she rated six or more of the hyperactivity-impulsivity symptoms as pretty much. The study subject is considered as having the combined subtype of ADHD, when he responds six or more pretty much for each of hyperactive- impulsive symptoms and inattention symptom (ie when he /she fulfill criteria for both inattentive and hyperactivity-impulsivity). The Disruptive Behavior Disorder Rating Scale was pretested for validity in our setup and was found to be easily understood by the participants with internal consistency (Cronbach's alpha = 0.8). ${ }^{35,37}$ The cut of point ${ }^{17}$ mentioned earlier came while we compute for each the subscale with SPSS. Symptoms on each item were considered positive if its score is at list 3 (ie pretty much). A person should have a total of six items with a score of three which equal to $18 .{ }^{35} \mathrm{~A}$ stressful life event was assessed using the List of Threatening Experiences Questionnaire (LTE-Q) which has 12item. ${ }^{19,28}$ LTE-Q is particularly recommended for use in psychiatric, psychological, and social studies in which other intervening variables such as social support, coping, and cognitive variables are of interest, and resources do not allow for the use of extensive interview measures of stress. ${ }^{36}$ The 12 types of stressful life events were collapsed in to six categories from which only two categories that were applicable for children were taken and entered separately into the model to determine which categories of events was most strongly associated with ADHD. To keep the quality of data, training was given to data collectors and supervisors, and a strict follow up was also done by the researcher during data collection. The Questionnaire was pre-test before the actual data collection. The current study has undergone following the Declaration of Helsinki's Ethical Principles for Medical Research involving human subjects. Ethical clearance was obtained from ethical review board of Ambo University (Ref. No AU/ T2344/11514). Respondents were informed about the purpose, procedure, risks, and benefits of the study and assured about the confidentiality of the data. We obtained informed verbal consent from parents/guardians before data collection. The informed verbal consent was approved 
by the ethical review board of Ambo University. Participants were also told as to have the right to withdraw from the study at any point during the interview if they did not feel comfortable with proceeding. We used codes instead of names for the sake of anonymity. The collected data were entered into Epi info version 7.1.2 and transferred to SPSS version 21 for analysis. Descriptive statistics were done. Binary logistic regressions were done and checked for association. Variables with P-value less than 0.2 at $95 \% \mathrm{CI}$, on bivariable analysis were entered to multivariable regression for further analysis. Variables with $\mathrm{p}$-value $<0.05$ was considered as statistically significant. (Figure 1)

\section{Operational Definition}

\section{Inattention}

When the child has always or very often at least six of the symptoms for inattention based on DSM-V which have persisted for at least 6 months to a maladaptive degree.

\section{Hyperactivity-Impulsivity}

When the child has, always or very often, at least six of the symptoms for Hyperactivity-Impulsivity based on DSM-V which have persisted for at least 6 months to a maladaptive degree.

\section{Previous Mental IIlness}

Information either subjectively told or medically confirmed any of mental health problem manifestation.

\section{Combined ADHD}

When a child has symptoms that met the criteria of both inattention and hyperactivity.

\section{Stressful Life Events on the Child}

The presence of stressful life events explained by experiencing one or more stressful life events set by Rahe and Holmes, in the last 6 months.

\section{Use of Substances at Conception}

In this study, it was defined as the use of at least one of the substance (cigarette, alcohol, khat, and other substances) throughout the time of pregnancy of the child being asked.

\section{Ever Use Substances}

In this study it was defined as use of at least one of specified substance (cigarette, alcohol, khat, and other substances) even once in life time.

\section{OPD}

(Out Patient Department) is the section of hospitals where patients who receive treatment without staying overnight are seen.

\section{Result}

\section{Socio-Demographic Characteristics of the Participants}

Out of 422 questionnaires, 407 filled completely, which gives a response rate of $96 \%$. Out of 407 respondents, 193 $(47 \%)$ were male. The age of the study participant ranges from 6 to 15 , with mean age (SD) $9.56( \pm 2.63)$. The majority, 380 (93\%) of the participants belong to Oromo ethnicity and 222 (54\%) were Orthodox Religion followers. The mean (SD) income of parents was about $3175(\approx \$ 93.38) \pm 1808$ Birr per month and the median was 2500 birr (\$73.53) per month while $206(50 \%)$ of parents earn less than or equal to 2500 Birr per month (Table 1).

\section{Psychosocial Factors}

Psychosocial factors that can stress the children's mind were assessed in this study. In this study, the presence of at least a single psychosocial stressor was a criterion to categorize the study subject as "a child with psychosocial stressor". Accordingly, about 116 (28\%) of respondents had one or more stressors. Of all stressors, death of a close relative, $34(8 \%)$ and presence of illness, and assault in the family $33(8 \%)$ were the major stressors affecting the study participants (Figure 2).

\section{Substance and Drug-Related Factors}

Alcohol was the only substance used by some of the children's mother during pregnancy. Thirty-three, which equates $8 \%$ of children's mothers, had used alcohol while they were in their womb.

\section{Clinical Factors}

Out of a total of 407 children involved in this study, 61 $(15 \%)$ of them had at least one of the clinical factors. Of which, $50(12 \%), 6(2 \%), 4(1 \%)$ are family history of mental illness, History of known chronic medical illness and previous history of mental illness respectively (Table 2).

\section{Maternal and Neonatal Factors}

The mean (SD) of maternal age at conception were 24.6 \pm 4.4 . Mothers of the study subjects who had 


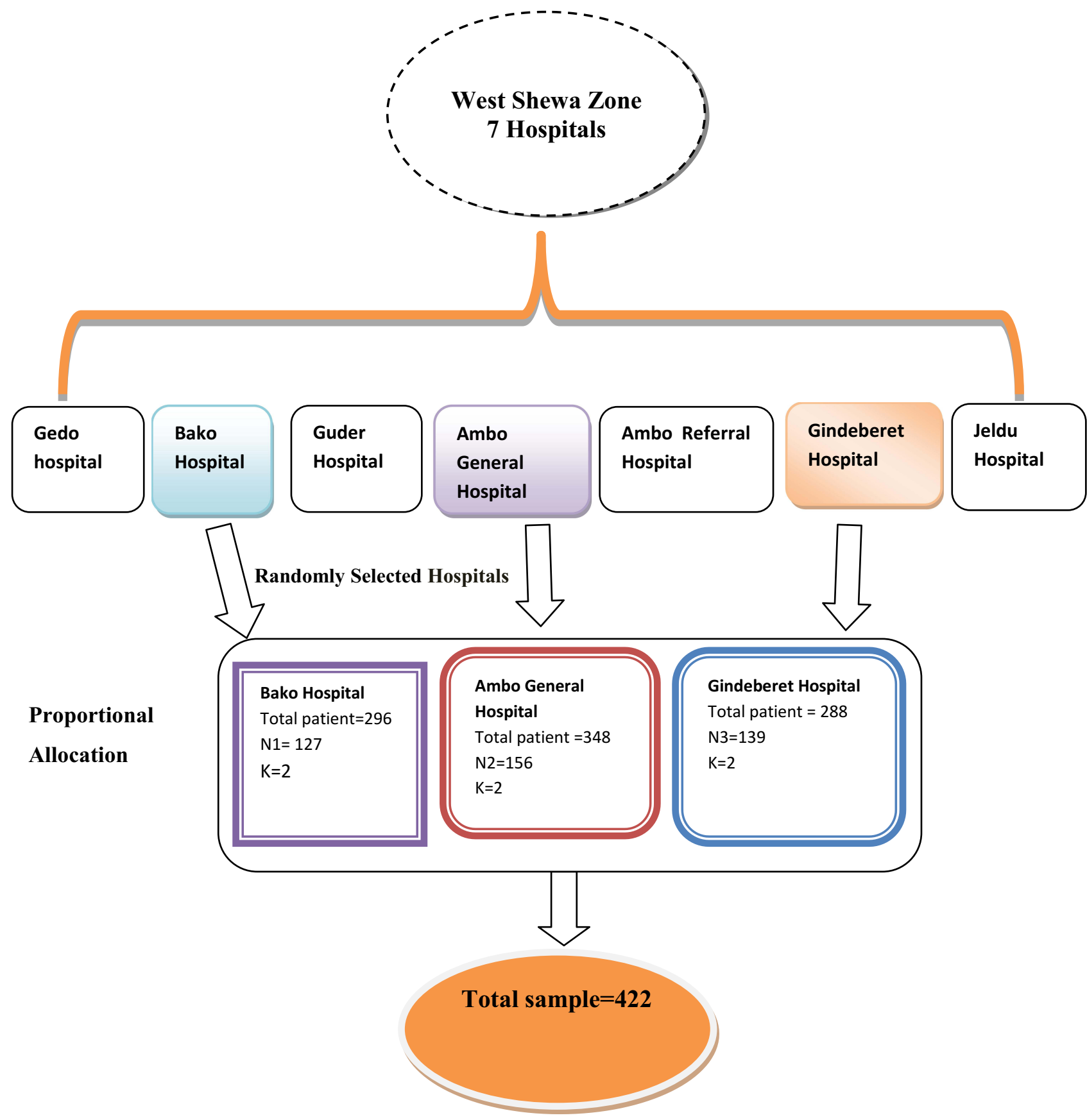

Figure I Schematic representation of sampling procedure.

Notes: Represents the data collection procedure. The top oval shape represents the seven hospitals in the West Shewa zone which was the study area. The lower boxes are to show each hospital in West Shewa zone. The three boxes located in a large single box represent randomly selected hospital from the seven hospitals, namely Bako hospital, Ambo General hospital and Gindeberet hospital. Total patient: total patient written under the three selected hospital is the total number of patients visited pediatric outpatient department (OPD) during study period. This was 296,348 and 288 for Bako Hospital, Ambo General Hospital and Gindeberet Hospital, respectively. NI: is sample taken from Bako hospital which was proportionally allocated. N2: is sample taken from Ambo general Hospital which was proportionally allocated. N3: sample taken from Gindeberet Hospital. This is also determined by proportional allocation. K: is the sampling interval, which is calculated and found to be 2 for each hospital. Total Sample: the total sample in the bottom oval shape represents the overall number of study subjects selected from the three hospitals, namely Bako Hospital, Ambo General Hospital and Gindeberet Hospital (ie, NI +N2+N3).

encountered complications of pregnancy were 44 (11\%), of which $20(45 \%), 9(20 \%)$ and $5(11 \%)$ preeclampsia, bleeding, and DM respectively. Majority of the study subjects, 321 (79\%), were born through SVD. The rest,
$52(13 \%), 26(6 \%)$, and $8(2 \%)$ were episiotomy, CS and instrumental respectively. Regarding neonatal factors, $42(10 \%)$ had perceived LBW and 27 (7\%) were preterm (Table 3) 
Table I Sociodemographic Characteristics of Children Attending Pediatric Outpatient Department of West Shewa Zone Hospitals, 2020

\begin{tabular}{|c|c|c|c|}
\hline \multicolumn{2}{|l|}{ Variables } & \multirow{2}{*}{$\begin{array}{r}\text { Frequency } \\
227\end{array}$} & \multirow{3}{*}{$\begin{array}{r}\text { Percent } \\
65.75 \\
44.25\end{array}$} \\
\hline Child's Age & $6-11$ & & \\
\hline & $12-15$ & 180 & \\
\hline \multirow[t]{2}{*}{ Child's Sex } & Male & 194 & 47.7 \\
\hline & Female & 213 & 52.3 \\
\hline \multirow[t]{4}{*}{ Religion } & Orthodox & 222 & 54.5 \\
\hline & Muslim & 16 & 3.9 \\
\hline & Protestant & 165 & 40.5 \\
\hline & Other & 4 & 1.0 \\
\hline \multirow[t]{4}{*}{ Ethnicity } & Oromo & 380 & 93.4 \\
\hline & Amhara & 13 & 3.2 \\
\hline & Gurage & 6 & 1.5 \\
\hline & Others & 8 & 2.0 \\
\hline \multirow{5}{*}{$\begin{array}{l}\text { Mother's education } \\
\text { level }\end{array}$} & Illiterate & 45 & II.I \\
\hline & Elementary & 229 & 56.3 \\
\hline & High school & 90 & 22.1 \\
\hline & Diploma & 30 & 7.4 \\
\hline & $\begin{array}{l}\text { Degree \& } \\
\text { above }\end{array}$ & 13 & 3.2 \\
\hline \multirow[t]{5}{*}{ Father's education } & Illiterate & 19 & 4.7 \\
\hline & Elementary & 175 & 43.0 \\
\hline & High school & 129 & 31.7 \\
\hline & Diploma & 39 & 9.6 \\
\hline & $\begin{array}{l}\text { Degree \& } \\
\text { above }\end{array}$ & 45 & 11.1 \\
\hline \multirow[t]{2}{*}{ Family's size } & $2-5$ & 304 & 74.69 \\
\hline & $>5$ & 103 & 25.31 \\
\hline \multirow[t]{2}{*}{ Family's monthly income } & $\leq 2876$ & 268 & 68.8 \\
\hline & $>2876$ & 139 & 34.2 \\
\hline \multirow{2}{*}{$\begin{array}{l}\text { Maternal age at } \\
\text { conception }\end{array}$} & $17-24$ & 216 & 53.1 \\
\hline & $25+$ & 191 & 46.9 \\
\hline
\end{tabular}

\section{Prevalence of ADHD}

The overall prevalence of ADHD among children was $8.4 \%$, $95 \% \mathrm{CI}(5.9,11.1)$. The combined subtype of ADHD was the most prevalent 21 (5.2\%), followed by hyperactive/impulsive, $10(2.5 \%)$ and inattentive, $3(0.7 \%)$. The prevalence of ADHD was higher among male children, 25 (73\%) than in females $9(0.26 \%)$. The hyperactive/impulsive subtype was higher in males than in females, with male to female ratio of $1: 4$, whereas, the inattentive subtype is higher in females, with male to female ratio of 1:3. ADHD was higher in children aged 6-11, when compared with those 12-15, 29 $(85 \%)$ versus $5(15 \%)$. Figure 3

\section{Factors Associated with ADHD}

To examine associations between ADHD and each of the determinant factors, all variables entered into multiple logistic regressions and checked for the association. Variables with a p-value less than 0.2 at $95 \% \mathrm{CI}$, on bivariate analysis, were entered to multinomial regression for further analysis. Accordingly, Age, sex, family's income, having psychological stressors, family history of mental illness, mothers' and fathers' educational level being primary and less, history of known chronic medical illness, maternal complication during pregnancy, perceived low weight at birth, and exposure of mothers to pesticide or insecticide during pregnancy was variables found to have fulfilled this criterion.

Finally, in multiple logistic regression, age 6-11 $(\mathrm{AOR}=3.38 \mathrm{CI}(1.22,9.39))$ being male $(\mathrm{AOR}=3.35, \mathrm{CI}$ (1.52, 7.38), having a family size greater than five $(\mathrm{AOR}=3.95$, CI $(1.44,10.11)$, low family income (AOR=19.74, 95\% CI $(2.71,143.75)$, presence of one or more psychosocial stressors $(\mathrm{AOR}=4.50 \quad(1.77,9.42))$, family history of mental illness $(\mathrm{AOR}=3.6,95 \% \mathrm{CI}$ $(1.78,8.21))$ and mothers having complication during pregnancy $(\mathrm{AOR}=\mathbf{3 . 0 5}$, CI $(\mathbf{1 . 1 0}, \mathbf{8 . 4 8}))$ are factors found to be associated with ADHD in this study. The following table shows the result of separate binary and multivariable analyses (Table 4).

\section{Discussion}

This study revealed that the overall prevalence of ADHD among children attending pediatric OPDs in hospitals found in West Shewa Zone, Central Ethiopia 8.4\%. At the country level, as to my knowledge, there is no similar study, but there are only two community-based studies done by HirbayeMokona Lola et al, 2019 and Rajalakshmi Murugan et al, 2016. The former one is done in rural an area of Guji zone, Southern Ethiopia, and the second one was conducted in selected Woredas of Jimma Zone, Southwest Ethiopia. The prevalence of this study is slightly higher as compared to the finding of the study conducted by HirbayeMokona Lola et al, 2019, which was $7.3 \%$. This discrepancy may be due to the difference in the study setting and study participants' age. In the study of Hirbaye et al children from age 6 to 17 years were involved while in the present study children of 6 to 15 years were involved). For the fact that prevalence of ADHD decreases as age increases. ${ }^{20,21}$ The prevalence of this study is low when compared with 


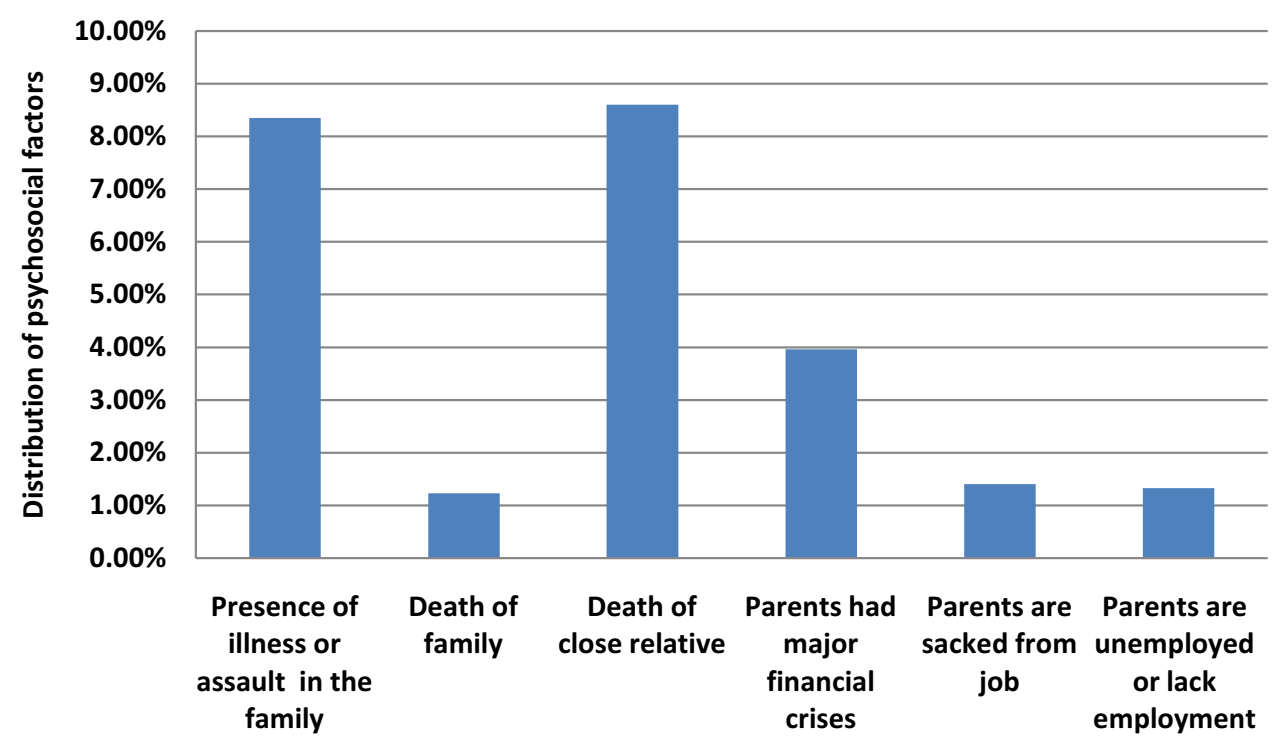

Figure 2 Psychosocial factors of children attending pediatric OPD of West Shewa hospitals, 2020.

Notes: Shows distribution of psychosocial factors (problems that high potential for stress) among the study subjects ( $N=407)$. As shown in the figure, the most common problem was death of close relative $(34(8.4 \%)$ ) and presence of illness or assault in the family $33(8.1 \%)$. Death of family was $5(\mathrm{I} .2 \%)$ among the study subjects shown (represented by the $2 \mathrm{nd}$ bar from the left). The $3 \mathrm{rd}$ bar (from right to left) represents children those parents had major financial crisis ( 16 ( $3.9 \%$ ). The 5 th bar (from the left) represents children those parents are sacked from job (6 in number, which equal to $1.5 \%$ ). The bar at the right represents children those parents are unemployed or lack employment $(22(5.4 \%)$.

that of the study done in Jimma Zone, by RajalakshmiMurugan et al, 2016, which was $13.7 \%$. This difference may be due to the difference in age categorization. In the case of Rajalakshmi Murugan et al, children between the ages 6 to 16 were included and there is also difference in the study setting. ${ }^{22}$

The prevalence of this study is similar to studies done in other African countries. For instance, the ADHD prevalence reported from some African countries like D.R. Congo (6\%), Uganda (11\%), and a review of epidemiology done in Africa (5-9\%) support this finding. ${ }^{22-24}$

Table 2 Distribution of Clinical Factors Among the Study Participants, 2020

\begin{tabular}{|l|c|c|c|}
\hline \multicolumn{2}{|l|}{ Variables } & Frequency & Percent \\
\hline Current history of mental illness & No & 406 & 99.8 \\
& Yes & I & 0.2 \\
\hline Previous history of mental illness & No & 403 & 99.0 \\
& Yes & 4 & 1.0 \\
\hline Family history of mental illness & No & 357 & 87.7 \\
& Yes & 47 & 12.3 \\
\hline History of known chronic medical & No & $40 I$ & 98.5 \\
illness & Yes & 6 & 1.5 \\
\hline
\end{tabular}

In a contrast, this finding is lower than the study done in Egypt, Kenya, and India which reported a prevalence of $19.7 \%, 13.1 \%$ and $11.32 \%$, respectively. ${ }^{25-27}$ This could be due to socio-demographic variables and methodological differences. For instance, in the study of Kenya, Adult ADHD Self-Report Scale (ASRS) screener was used to screen children in the community which is obviously different from the disruptive behavioral disorder rating scale used in this study.

When compared with studies across Europe and the rest of the World, it is in line with the systemic review done by $\mathrm{R}$. Thomas which reported an overall pooled prevalence of $7.2 \%$ and the cross sectional study done in Turkey, South Korea, Spain, China and Iran which reported 8\%, 8.5\%, $6.8 \%, 6.3 \%$, and $9.8 \%$, respectively. ${ }^{21,23,28-30}$

On the other hand, the prevalence of this study was higher than the worldwide pooled prevalence study of ADHD done by Polanczyk G, et al, which was 5.29\%, study done in Italy which reported the pooled prevalence of ADHD to be $2.9 \%$, and study done in Saudi Arabia which reported Prevalence of ADHD to be 3.4\%.,31,32 One of the reasons for this discrepancy could be due to the absence of assessment of impairment in this study. Another reason could be due to variation of participants' age range as the study participants' age ranges above 15 in some of these literatures. 
Table 3 Distribution of Maternal and Neonatal Factors Among Study Participants

\begin{tabular}{|c|c|c|c|}
\hline \multicolumn{2}{|l|}{ Variables } & \multirow{2}{*}{$\begin{array}{r}\text { Frequency } \\
216 \\
191\end{array}$} & \multirow{2}{*}{$\begin{array}{r}\text { Percent } \\
53.1 \\
46.9\end{array}$} \\
\hline $\begin{array}{l}\text { Maternal age at } \\
\text { conception }\end{array}$ & $\begin{array}{l}17-24 \\
\geq 25\end{array}$ & & \\
\hline $\begin{array}{l}\text { Have you had history of } \\
\text { medical illness during } \\
\text { pregnancy }\end{array}$ & $\begin{array}{l}\text { No } \\
\text { Yes }\end{array}$ & $\begin{array}{r}376 \\
31\end{array}$ & $\begin{array}{r}92.4 \\
7.6\end{array}$ \\
\hline $\begin{array}{l}\text { Complication during } \\
\text { pregnancy }\end{array}$ & $\begin{array}{l}\text { No } \\
\text { Yes }\end{array}$ & $\begin{array}{r}363 \\
44\end{array}$ & $\begin{array}{l}91.9 \\
10.8\end{array}$ \\
\hline Type of complication & $\begin{array}{l}\text { Bleeding } \\
\text { Preeclampsia } \\
\text { DM } \\
\text { Other }\end{array}$ & $\begin{array}{r}9 \\
20 \\
5 \\
3\end{array}$ & $\begin{array}{r}20.45 \\
45.45 \\
11.36 \\
6.8\end{array}$ \\
\hline Mode of delivery & $\begin{array}{l}\text { Spontaneous } \\
\text { Vaginal } \\
\text { CS } \\
\text { Episiotomy } \\
\text { Instrumental }\end{array}$ & $\begin{array}{r}321 \\
26 \\
52 \\
8\end{array}$ & $\begin{array}{r}78.9 \\
\\
6.4 \\
12.8 \\
2.0\end{array}$ \\
\hline Born before $32 \mathrm{Wks}$ & $\begin{array}{l}\text { No } \\
\text { Yes }\end{array}$ & $\begin{array}{r}380 \\
27\end{array}$ & $\begin{array}{r}93.4 \\
6.6\end{array}$ \\
\hline $\begin{array}{l}\text { Perceived low weight at } \\
\text { birth }\end{array}$ & $\begin{array}{l}\text { No } \\
\text { Yes }\end{array}$ & $\begin{array}{r}365 \\
42\end{array}$ & $\begin{array}{l}89.7 \\
10.3\end{array}$ \\
\hline $\begin{array}{l}\text { Encountered any } \\
\text { problem soon after } \\
\text { delivery }\end{array}$ & $\begin{array}{l}\text { No } \\
\text { Yes }\end{array}$ & $\begin{array}{r}355 \\
52\end{array}$ & $\begin{array}{l}97.22 \\
12.78\end{array}$ \\
\hline Cried soon after delivery & $\begin{array}{l}\text { No } \\
\text { Yes }\end{array}$ & $\begin{array}{l}118 \\
289\end{array}$ & $\begin{array}{l}29.00 \\
71.00\end{array}$ \\
\hline $\begin{array}{l}\text { Mother exposed to } \\
\text { pesticide or insecticide } \\
\text { during pregnancy }\end{array}$ & $\begin{array}{l}\text { No } \\
\text { Yes }\end{array}$ & $\begin{array}{r}381 \\
26\end{array}$ & $\begin{array}{r}93.6 \\
6.4\end{array}$ \\
\hline
\end{tabular}

Children below the age of 12 are more likely to have ADHD when compared with the elders, ie, age 6-11 $(\mathrm{AOR}=3.38 \mathrm{CI}(1.22,9.39))$. This is also seen in several other studies. For instance, in the study of Wamulugwa et al, children below age 10 are seven times more likely to have ADHD when compared with age above $10 .^{29} \mathrm{~A}$ study done in shanghai also support this finding, showing a high prevalence of ADHD among children aged 7-10, when compared with older ages. ${ }^{30}$ This is due to the fact that symptoms of ADHD gradually relieved over time. As the age increases, the hyperactive symptom which is easily noticed by parents decreases. ${ }^{2,3}$

Regarding the distribution of ADHD across sexes, there were only 2 girls and 1 boy with inattentive
ADHD. These numbers are too small for a meaningful statistical comparison. But, if we try to compare with this finding males are about three times more likely to develop ADHD than females $(\mathrm{AOR}=3.35$, CI $(1.54$, 7.40)). In addition, male children tend to have a hyperactive subtype of ADHD (M:F=4:1) whereas, two in three inattentive ADHD was female. This is one of the most common and extensively studied factors associated with ADHD. It was seen in almost every epidemiological studies of ADHD. For instance, this study is in line with the study of Lola et al which found out that males have about two times risk of developing ADHD than females. ${ }^{20}$ A study done in Egypt has also shown male to female distribution of ADHD to be 1:7. ${ }^{25}$ This could be due to neuroanatomical differences between males and females, as neurochemical factors like dopamine, noradrenergic system and epinephrine are postulated as etiology of ADHD. ${ }^{2}$ The other possible factor for the high prevalence of ADHD in males could be due to observer bias since males are more likely to present with more outward behaviors like hyperactivity, impulsivity and physical aggression) than females and females are more likely to be present with more inward behavior (such as being withdrawn, being in a state of anxiety, and having low self-esteem) than males. So the internalized symptoms may remain unnoticed in females. ${ }^{31}$

In our study, family size is found to be associated with ADHD. According to this finding, children from a family size of greater than five are about four times more likely to develop ADHD, when compared with those from five or less family size $(\mathrm{AOR}=3.95$, $\mathrm{CI}(1.44,10.11)$. This finding is consistent with the finding of Fathia Mohamed El-Nemr et al, which showed having family size greater than four is significantly associated with ADHD. ${ }^{25,30}$ This may be due to the fact that children with larger family size may lack adequate care and support and this results in behavioral and mental problems like ADHD. ${ }^{33,39,40}$ In addition, a higher prevalence of ADHD in the larger family maybe due to the fact that ADHD is largely genetic and so the parents might also have ADHD, which is associated with having children younger and having more children.

Family income is found to be significantly associated with ADHD in this study. Children of family's income less than or equal to ETB $\leq 2877$ are more likely to have ADHD when compared to the higher-income families $(\mathrm{AOR}=3.47(1.25,10.10))$. This is consistent with several studies done previously. Low family socio economic status 


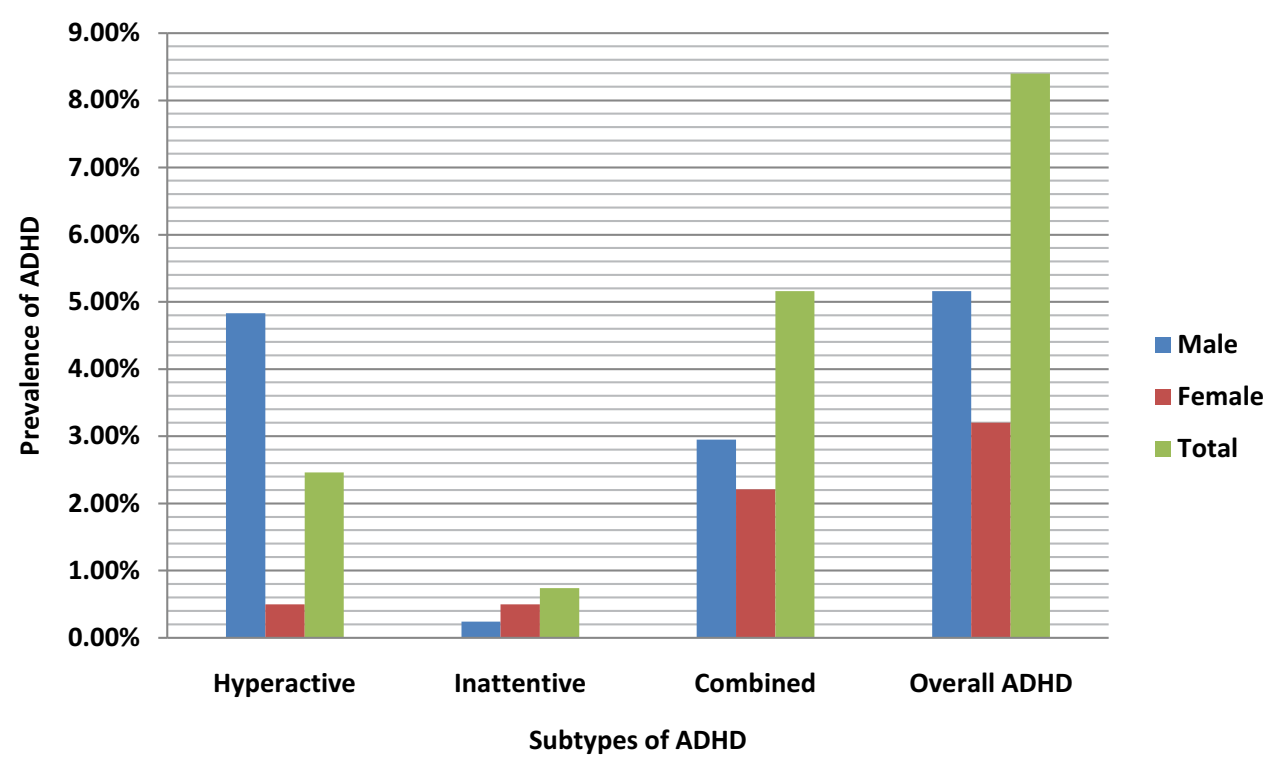

Figure 3 Prevalence and subtype of ADHD among children attending pediatric OPD of hospitals in West Shewa, 2020 (N=407).

Notes: This figure conveys three messages, the overall prevalence of ADHD, the distribution of subtypes of ADHD among the study subjects and the male and female variation of each subtypes. The first three bars (from the left) represent the distribution of hyperactive subtypes of ADHD. The green one represents the distribution among males, which was 8 in number (1.96\%) and the yellow bar represents the distribution among females which was 2 in number (0.5\%). The red one represents the sum of male and females which equals 10 in number (2.5\%). The second three bars (from the left) represent the distribution of combined subtype of ADHD among the study subjects. The green (I6 (3.9\%)) and yellow (5 (I.22\%)) represents the distribution among male and female, respectively; while the red (2I $5.2 \%))$ is for the sum (total) of male and female. The third three bars represent the distribution of inattentive subtype of ADHD among the study subjects. The green (I $(0.25 \%))$, yellow $(2(0.5 \%))$ and red $(3(0.7 \%)$ represent again the distribution among male, female and total respectively. The three bars from the right represent the overall prevalence of ADHD among the study subjects. Here again, the green $(25(6.14 \%))$ and yellow $(9(2.21 \%))$ represents the prevalence of ADHD among male and female respectively, while the red (34 (8.4\%)) shows the overall prevalence of ADHD among both male and female.

was found to be significantly associated with ADHD in the study of Lola et al. ${ }^{20}$ A review of literature done by Kapil Sayaletal also found that children from low socioeconomy had 1.5 to 4 times more likely to have ADHD. ${ }^{34}$ A study done in the UK on the Socioeconomic Associations with ADHD found that the risk of developing ADHD will be doubled if their parents were in financial problem during infantile age. ${ }^{35}$ This is also found in the study done in Egypt. ${ }^{25}$ Similarly, a recent study done by Zablotskyetalacross different ethnic groups found that children live in families at $100 \%$ or more of Federal poverty level is more likely to develop ADHD. ${ }^{36}$ This may be due to the fact that low socioeconomic status contributed to increased risk of having malnutrition, infection, and various pregnancy and newborn complication which leads to different psychiatric illnesses like ADHD. ${ }^{2}$ The high rate of ADHD among poor families may also due to its strong association with genes as the parents of the child might have affected by ADHD and poor due unemployment and sustaining severe accidents as adverse effects of ADHD on adults.

Having one or more psychosocial stressors is one of the factors associated with ADHD in this study. Children with one or more psychosocial stressors like the death of parents, the presence of illness in the family, and financial crisis in the family are about five times more likely to have $\operatorname{ADHD}(\mathrm{AOR}=4.50(1.77,9.42))$. This is in line with the longitudinal study of Wüstner et al, where more incidence of ADHD was noted in children from low socioeconomic status. ${ }^{34}$ This is due to the fact that stressors cause various neuroendocrine responses which in turn predispose to several mental illnesses as explained by Kaplan and Sadocks. ${ }^{2}$

We found no association between maternal substance use and ADHD. This is in agreement with the finding of other studies done in Ethiopia and other parts of the world. $^{20,37}$ However, maternal use of psychoactive substance was associated with ADHD in other studies. ${ }^{43}$ This discrepancy may be due to sociodemographic variation of the study subjects as evidenced by only $33(8 \%)$ of the mothers of the study subject had ever used alcohol during pregnancy and no use of cigarette at all in our case.

Although the type of mental illness was not known due to family's perception and poor mental health awareness level, the presence of a family history of any mental illness was found to be associated with ADHD. In this study, children having a family history of mental illness are more likely to have ADHD when compared to others 
Table 4 Distribution of Factors Associated with ADHD Among Study Participants By a Separate Binary and Multivariable Analysis, 2020

\begin{tabular}{|c|c|c|c|c|c|}
\hline \multirow[t]{2}{*}{ Variables } & \multicolumn{2}{|c|}{ ADHD } & \multicolumn{2}{|c|}{ C/I (95\%) } & \multirow[t]{2}{*}{ P-value } \\
\hline & With ADHD & Without ADHD & COR & AOR & \\
\hline \multicolumn{6}{|l|}{ Age } \\
\hline $6-11$ & 27 & 200 & $3.34(1.14,7.85)$ & $3.38(1.22,9.39)$ & $0.020 * *$ \\
\hline$>11$ & 7 & 173 & I & 1 & \\
\hline \multicolumn{6}{|l|}{ Sex } \\
\hline Male & 25 & 169 & $3.35(1.52,7.38)$ & $3.07(1.16,8.11)$ & $0.023 * *$ \\
\hline Female & 9 & 204 & I & I & \\
\hline \multicolumn{6}{|l|}{ Ethnicity } \\
\hline Oromo & 31 & 349 & $0.62(0.72,5.22)$ & $1.31(0.07,25.13)$ & \\
\hline Amhara & 1 & 12 & $0.58(0.03,10.86)$ & $1.61(0.035,7.56)$ & \\
\hline Gurage & 1 & 5 & $1.4(0.70,8.12)$ & $4.74(0.09,4.7 I)$ & \\
\hline Others & 1 & 7 & I & & \\
\hline \multicolumn{6}{|l|}{ Religion } \\
\hline Orthodox & 14 & 208 & $0.00(0.000,0.000)$ & $0.47(0.029,7.55)$ & \\
\hline Muslim & 1 & 15 & $0.512(0.25,1.06)$ & $1.73(0.77,3.88)$ & \\
\hline Protestant & 19 & 146 & $0.517(0.06,4.10)$ & $0.000(0.000)$ & \\
\hline Other & 0 & 4 & 1 & I & \\
\hline \multicolumn{6}{|l|}{ Mother's Education Level } \\
\hline Primary and less & 29 & 245 & $3.03(1.15,8.02)$ & $4(1.20,8.76)$ & 0.724 \\
\hline High school and above & 5 & 128 & I & I & \\
\hline \multicolumn{6}{|l|}{ Father's education } \\
\hline Primary and less & 20 & 174 & $1.63(0.80,3.33)$ & $1.04(0.28,3.18)$ & 0.412 \\
\hline High school and above & 14 & 199 & 1 & 1 & \\
\hline \multicolumn{6}{|l|}{ Family's size } \\
\hline$>5$ & 28 & 185 & $4.74(1.92,10.25)$ & $3.95(1.44,10.11)$ & $0.008 * *$ \\
\hline $2-5$ & 6 & 188 & 1 & 1 & \\
\hline \multicolumn{6}{|l|}{ Family's monthly income } \\
\hline$\leq 2877$ ETB $(\$ 84.62)$ & 28 & 224 & $3(1.26,7.68)$ & $3.47(1.25,10.10)$ & $0.022 * *$ \\
\hline$>2877 \mathrm{ETB}(\$ 84.62)$ & 6 & 149 & I & 1 & \\
\hline \multicolumn{6}{|l|}{ Maternal age at conception } \\
\hline $17-24$ & 19 & 197 & $0.73(0.56,0.29)$ & $0.73(0.2 \mathrm{I}, 2.52)$ & \\
\hline$\geq 25$ & 15 & 176 & 1 & 1 & \\
\hline \multicolumn{6}{|c|}{$\begin{array}{l}\text { Having one or more psychosocial } \\
\text { stressors }\end{array}$} \\
\hline Yes & 17 & 77 & $4.32(2.11,8.87)$ & $4.50(1.77,9.42)$ & $0.001 * *$ \\
\hline No & 17 & 296 & I & I & \\
\hline \multicolumn{6}{|c|}{ Family history of mental illness } \\
\hline Yes & 12 & 35 & $4.10(1.78,9.10)$ & $3.6(1.78,8.21)$ & $0.044^{* *}$ \\
\hline No & 22 & 338 & I & 1 & \\
\hline \multicolumn{6}{|c|}{$\begin{array}{l}\text { Mother used psychoactive substance } \\
\text { during pregnancy }\end{array}$} \\
\hline Yes & 11 & 22 & $7.63(3.30,17.63)$ & $2.14(0.65,6.20)$ & 0.216 \\
\hline No & 23 & 351 & I & 1 & \\
\hline
\end{tabular}

(Continued) 
Table 4 (Continued).

\begin{tabular}{|c|c|c|c|c|c|}
\hline \multirow[t]{2}{*}{ Variables } & \multicolumn{2}{|c|}{ ADHD } & \multicolumn{2}{|c|}{ C/I (95\%) } & \multirow[t]{2}{*}{ P-value } \\
\hline & With ADHD & Without ADHD & COR & AOR & \\
\hline \multicolumn{6}{|c|}{$\begin{array}{l}\text { Mother had history of medical illness } \\
\text { during pregnancy }\end{array}$} \\
\hline Yes & 2 & 29 & $1.87(0.43,8.10)$ & $0.99(0.15,6.09)$ & 0.781 \\
\hline No & 32 & 344 & 1 & I & \\
\hline \multicolumn{6}{|c|}{$\begin{array}{l}\text { Mother had complication during } \\
\text { pregnancy }\end{array}$} \\
\hline Yes & 11 & 33 & $7.63(3.30,17.63)$ & $3.05(1.10,8.48)$ & $0.011 * *$ \\
\hline No & 23 & 340 & 1 & 1 & \\
\hline \multicolumn{6}{|c|}{ Born before $32 \mathrm{Wks}$} \\
\hline Yes & 10 & 44 & $3.11(1.39,6.95)$ & $1.47(0.38,5.63)$ & 0.585 \\
\hline No & 24 & 329 & $\mathrm{I}$ & & \\
\hline \multicolumn{6}{|c|}{ Perceived low weight at birth } \\
\hline Yes & 13 & 50 & $4.00(1.88,8.49)$ & $2.66(0.84,8.45)$ & 0.097 \\
\hline No & 221 & 323 & 1 & I & \\
\hline \multicolumn{6}{|c|}{$\begin{array}{l}\text { Encountered any problem soon after } \\
\text { delivery }\end{array}$} \\
\hline Yes & 8 & 44 & $2.29(0.98,5.38)$ & $2.29(0.74,7.08)$ & 0.150 \\
\hline No & 26 & 328 & $\mathrm{I}$ & 1 & \\
\hline \multicolumn{6}{|c|}{ Cried soon after delivery } \\
\hline No & 19 & 99 & $3.5 I(1.71,7.17)$ & $2.16(0.74,6.00)$ & 0.137 \\
\hline Yes & 15 & 274 & I & I & \\
\hline \multicolumn{6}{|c|}{$\begin{array}{l}\text { Mother exposed to pesticide or } \\
\text { insecticide during pregnancy }\end{array}$} \\
\hline Yes & 3 & 23 & $1.47(0.42,5.18)$ & $0.58(0.06,3.4 \mathrm{I})$ & 0.548 \\
\hline No & 13 & 350 & 1 & 1 & \\
\hline
\end{tabular}

Note: **Has statistically significant association.

Abbreviation: ETB, Ethiopian Birr.

$(\mathrm{AOR}=3,695 \% \mathrm{CI}(1.78,8.21))$. This is consistent with a study done in Egypt which showed the presence of significant association between ADHD and family history of ADHD. ${ }^{26}$ A study done in Beirut has also shown as ADHD was associated with a positive family psychiatric history. ${ }^{38}$ In the longitudinal study of Wüstner et al, one of the most recent studies, parents with severe mental health disorder are more likely to have children or adolescents having ADHD symptoms. ${ }^{33}$ The reason for this association is due to the fact that gene contributes a lot as a causal factor of ADHD as any other mental illness. The heritability of ADHD is believed to be one of the highest in the disorders of psychiatry, $75-80 \%{ }^{27,42}$ Thus, children found to have mental illness in this study could have family history of ADHD and other mental illnesses as a comorbidity. ${ }^{2,7,48}$
We have also tested whether maternal complications like preeclampsia, DM, bleeding, STI, and others have effects on offspring. Then, we have found that maternal complication during pregnancy was also another factor found to be significantly associated with ADHD. Accordingly, children whose mothers had complication of pregnancy while they were in the womb were three times more likely to have ADHD when compared with their counterparts $(\mathrm{AOR}=3.05, \mathrm{CI}(1.10,8.48))$. This finding is in line with the study done in Uganda where a history of maternal abnormal vaginal discharge during pregnancy was found to be significantly associated with ADHD. ${ }^{44}$ Another study that supports this finding is a case control study done in Brazil, where perinatal complication was found to be significantly associated with ADHD. ${ }^{30,45}$ In a contrast, this finding disagrees with a previous study 
where complications of pregnancy did not associated with ADHD. ${ }^{20}$ This discrepancy may be due to variation in sociodemographic characteristics of the study subjects. A possible explanation of the association of complication of pregnancy and ADHD is mothers having complications like preeclampsia, DM, bleeding, and others may leads to maternal stress which in turn can affects the neurodevelopment of the fetus and predispose to ADHD. ${ }^{46,47}$

In this study, neonatal factors like perceived LBW, being preterm, and not crying soon after delivery were not associated with ADHD. These are also not associated in another study done in Guji zone, western Ethiopia. ${ }^{20}$ This finding is also consistent with some of the studies done outside Ethiopia. For instance, in the study done in DR Congo, a child's birth weight, abnormal neonatal period, and infant abnormal development are not significantly associated with ADHD. ${ }^{22}$ Low birth weight was not found to be associated with ADHD in the Iranian study also. ${ }^{23}$ However, being preterm and low birth weight were found to be associated with the Egyptian study. ${ }^{26}$ This variation may be due to sociodemographic variation of the study participants.

\section{Conclusion}

The prevalence of ADHD among children attending pediatric OPDs at West Shewa Zone Hospitals is similar to the rest of the world; and it is significantly associated with younger age, sex being male, large family size, low SES, having psychosocial stressors, having a family history of mental illness and history of complication during pregnancy. This finding shows that ADHD is undeniably a considerable public health issue that requires great emphasis.

\section{Abbreviation}

ADHD, attention deficit/hyperactivity disorder; AOR, adjusted odds ratio; APA, American Psychiatric Association; CI, confidence interval; DBRS, Disruptive Behavioral Rating Scale; DALYs, disability adjusted life years; DSM, Diagnostic and Statistical Manual of Mental Disorder; IRB, Institutional Review Board; LBW, low birth weight; LTE-Q, List of Threatening Experiences Questionnaire; OPD, out patient department; RR, relative risk; USA, United States of America.

\section{Data Sharing Statement}

The datasets during and/or analyzed during the current study are available from the corresponding author on reasonable request.

\section{Ethics Approval and Consent to Participate}

This study was approved by the ethical review board of College of Medicine and Health Sciences, Ambo University. Informed consent to participate in the study was obtained from all participants' parent/guardian. Those with ADHD screening positive were linked to Psychiatry clinic for further evaluation.

\section{Limitation}

Some independent variables like neonatal and maternal factors discussed in this study subjected to recall bias. Psychosocial factors that we tested adjusting LTE-Q to children are not standard and need further evaluation by other researchers. In addition, the impairment criteria were not included in this study and might have slightly raised the prevalence found so far.

\section{Acknowledgments}

The authors would like to thank Ambo University for allocating fund to conduct the study. We would also like to express our heartfelt gratitude to all institutions and individuals who supported us during this research work. Last but absolutely not the least; we would like to thank study participants for their valuable time and willingness to provide full information required for this research.

\section{Funding}

Funding for the research was provided by Ambo university's research, consultancy, and community service director office. Besides, financial support, the funding body had no role in the design of the study and collection, analysis and interpretation of data and in writing the manuscript.

\section{Disclosure}

The authors declare that they have no competing interests in this work.

\section{References}

1. Bradshaw LG, Kamal M. Prevalence of ADHD in Qatari school-age children. J Atten Disord. 2014. doi:10.1177/1087054713517545

2. Kaplan and Saocks. Synopsis of Psychiatry. 11th ed. Newyork: Wolters Kluwer; 2015.

3. America's Children and the Environment. Neurodevelopmental Disorders. 3rd ed. 2015.

4. American Psychiatric Association. Diagnostic and Statistical Manual of Mental Disorders (DSM V-TR). Washington, DC; 2013.

5. WADA-World Anti-Doping Program. Attention Deficit Hyperactivity Disorder (ADHD) in Children and Adults: TUEC Guidelines - ADHD - Version 6.0. 2017. 
6. Wilens TE, Martelon MK, Joshi G. Does ADHD predict substance-use disorders? A 10-year follow-up study of young adults with ADHD. J Am Acad Child Adolesc Psychiatr. 2011;50 (6):543-553. doi:10.1016/j.jaac.2011.01.021

7. Polanczyk G, de Lima MS, Horta BL, Biederman J, Rohde LA. The worldwide prevalence of ADHD: asystematic review and metaregression analysis. AM J Psychiatry. 2007;164(6):942-948. doi:10.1176/ ajp.2007.164.6.942

8. Pelham F, Foster EM, Robb JA. The economic impact of attention-deficit/hyperactivity disorder in children and adolescents. J Pediatr Psychol. 2007;32(6):711-727. doi:10.1093/jpepsy/jsm022

9. Coghill D, Soutollo C, D'Aubouson C, Preuss U. Impact of attention deficit /hyperactivity disorder on the patient and family: result from a European survey. Child Adolesc Psychiatry Ment Health. 2008;2 (1):31. doi:10.1186/1753-2000-2-31

10. Amaravath T, Murugan M. Attention deficit hyperactivity disorder. Biosci Trends. 2019;12(3).

11. U.S. Department of Education. How Does ADHD Affect School Performance?Identifying and Treating Attention Deficit Hyperactivity Disorder: a Resource for School and Home; 2009. https://www2.ed.gov/about/offices/list/osers/osep/products.html. Accessed July 5, 2021.

12. Agnieszka KC. The cognitive effects of ADHD on learning an additional language. GOVOR. 2018;35:2.

13. Harpin VA. The effect of ADHD on the life of an individual, their family, and community from preschool to adult life. Arch Dis Child. 2005;90(Suppl I):i2-i7. doi:10.1136/adc.2004.059006

14. Young S, Fitzgerald M, Postma MJ. ADHD: Making the Invisible Visible'an Expert White Paper on Attention-Deficit Hyperactivity Disorder. Brussels; 2013.

15. Anette P, Kvist H, Skyt N, Marianne S. IZA the effects of children's ADHD on parents' relationship dissolution and labor supply. 2011IZA Discussion Paper No. 6092.

16. Chacko A, Kofle\& M, Jarrett M. Improving outcomes for youth with ADHD: a conceptual framework for combined neurocognitive and skill-based treatment approaches'clin child fampsycholauther manuscript available in PMC. December 1, 2015.

17. Vibert S, Your Attention please: the social and economic impact of ADH. Demo 2018 demos. Mill Street, London.

18. Pelham WE Jr, Gnagy EM, Greenslade KE, Milich R. Teacher ratings of DSM-III-R symptoms for the disruptive behavior disorders. $J \mathrm{Am}$ Acad Child Adolesc Psychiatry. 1992;31(2):210-218. doi:10.1097| 00004583-199203000-00006

19. Brugha TS, Cragg D. The list of threatening experiences: the reliability and validity of a brief life events questionnaire. ActaPsychiatricaScandinavica. 1990. doi:10.1111/j.1600-0447.1990. tb01360.x

20. Lola HM, Habte B, Abebaw G, Aemro Z. Attention deficit hyperactivity disorder (ADHD) among children aged 6 to 17 years old living in Girja District, Rural Ethiopia. Hindawi Behav Neurol. 2019:8. Article ID 1753580. doi:10.1155/2019/1753580

21. Rajalakshmi M, Tiruneh F, Theresse M, Flores Merino MV. Prevalence of attention deficit hyperactivity developmental disorder among children in jimma zone, oromia region, South West Ethiopia. Int J Curr Res. 2016;8(05):30582.

22. Chinawa JM, Obu HA. ADHD - New Directions in Diagnosis and Treatmen Epidemiology of Attention Deficit/Hyperactivity Disorder. 2015. doi:10.5772/61016

23. Kashala E, Tylleskar T, Elgen I, Kayembe KT, Sommerfelt K. Attention deficit and hyperactivity disorder among school children in Kinshasa, Democratic Republic of Congo. Afr Health Sci. 2005;5 (3):172-181. doi:10.5555/afhs.2005.5.3.172

24. Wamulugwa J, Kakooza A, Bakeera SK, Nalugya J. Prevalence and associated factors of attention deficit hyperactivity disorder (ADHD) among Ugandan children; a Cross-Sectional Study. Child Adolesc Psychiatry Ment Health. 2017;11(1):18. doi:10.1186/s13034-017-0155-6
25. Bakare MO. Attention deficit hyperactivity symptoms and disorder (ADHD) among African children: a review of epidemiology and co-morbiditie. Afr J Psychiatry. 2012;15(5):358. doi:10.4314/ajpsy. v15i5.45

26. El-Nemr FM, Hassan SB, Mohamed S. Prevalence of attention deficit hyperactivity disorder in children. Sci J Public Health. 2015;3 (2):274. doi:10.11648/j.sjph.20150302.28

27. Jenkins R, Othien C, Ongeri L, Ogutu B, Sifuna P, Mboroki J. Attention deficit hyperactivity disorder symptom self-report in adults in Kenya and its associated risk factors, an analysis from a household survey in a demographic surveillance site. GLOBAL MENT HEALTH. 2014.

28. Venkata JA, Panicker AS. Prevalence of attention deficit hyperactivity disorder in primary school children. Indian J Psychiatry. 2013;55 (4):338-342. doi:10.4103/0019-5545.120544

29. Thomas R. Prevalence of attention-deficit/ hyperactivity disorder: a systematic review and meta-analysis. Am Acad Pediatr. 2015;135(4).

30. Zorlu A, Unlu G, Cakaloz B, Zenci M, Buber A, Isildar Y. The prevalence and comorbidity rates of ADHD among school-age children in Turkey. J Atten Disord. 2015;24(9):1237-1245. doi:10.1177/ 1087054715577991

31. Kim MJ, Park I, Lim MH, Paik KC, Cho S, Kwon H-J. Prevalence of ADHD in Korean children. J Korean Med Sci. 2017;32(3):401-406. doi:10.3346/jkms.2017.32.3.401

32. Catalá-López SP, Ridao M, Gabrial SG, Ricard GM, Miguel AC, Catalá MA. Prevalence of attention deficit/hyperactivity among children and adolescents in Spain: a systematic review and metaanalysis of epidemiological studies. BMC Psychiatry. 2012;12(1):168. doi:10.1186/1471-244X-12-168

33. Liu A. The prevalence of attention deficit/ hyperactivity disorder among chinese children and adolescent. SCiEnTiFiCRepoRTs. 2018;8:11169.

34. Abolhassanzadeh M, Shafiee-Kandjani VZ, Molavi P, Movahhed FS, Noorazar G, Basharpoor S, The prevalence and risk factors of attention deficit hyperactivity disorder among the elementary school students in Ardabil, Iran, in 2011-2012. J Anal Res Clin Med. 2016;4 (3):146-152. doi:10.15171/jarcm.2016.024

35. Reale L, Bonati M. ADHD prevalence estimates in Italian children and adolescents: a methodological issue. Ital J Pediatr. 2018;44 (1):108. doi:10.1186/s13052-018-0545-2

36. Albatti TH, Zhour A, Norah A, Anjod A, Jowhar A, Rawan A. Prevalence of attention deficit/hyperactivity disorder among primary school-children in Riyadh, Saudi Arabia. Int J Pediatr Adolesc Med. 2017;4:91e9.

37. Jin W, Yasong D, Zhong X, David C. Prevalence and contributing factors to attention deficit hyperactivity disorder: a study of five- to fifteen-year-old children in Zhabei District, Shanghai. Asia Pac Psychiatry. 2014;397-404.

38. Wüstner A, Otto C, Schlack R. Risk and protective factors for the development of ADHD symptoms in children and adolescents: results of the longitudinal BELLA study. PLoS One. 2019;14(3):e0214412. doi:10.1371/journal.pone.0214412

39. Pheula GF, Rohde LA, Schmitz M. Are family variables associated with ADHD, inattentive type? A case-control study in schools. Eur Child Adolesc Psychiatry. 2011;20(3):137-145. doi:10.1007/s00787011-0158-4

40. Bedard K, Witman A. Family structure and the gender gap in ADHD. Rev Econ Househ. 2020;18(4):1101-1129. doi:10.1007/s00787-0110158-4

41. Russell AE, Ford T, Russell G. Socioeconomic associations with ADHD: findings from a mediation analysis. PloS One. 2015;10(6): e0128248. doi:10.1371/journal.pone. 0128248

42. Zablotsky B, Josephine M. Racial and ethnic differences in the prevalence of attention-deficit/hyperactivity disorder and learning disabilities among u.s. children aged 3-17 years. NCHS Data Brief. 2020;358. https://www.cdc.gov/nchs/products/index.htm. 
43. Umar MU, Obindo JT, Omigbodun OO. Prevalence and correlates of ADHD among adolescent students in Nigeria. J Atten Disord. 2015. doi:10.1177/1087054715594456

44. Ghossoub E, Ghandour LA. Prevalence and correlates of ADHD among adolescents in a Beirut community sample: results from the BEI-PSY Study. Child Adolesc Psychiatry Ment Health. 2017;11:20. doi:10.1186/s13034-017-0156-5

45. Ketzer CR, Gallois C, Martinez AL, Rohde L, Schmitz M. Is there an association between perinatal complications and attention-deficit/hyperactivity disorder-inattentive type in children and adolescents? Rev Bras Psiquiatr. 2012;34(3):321-328. doi:10.1016/j.rbp.2012.01.001
46. Castejón OJ, Galindez P, Torres IA, Leal J, Villasmil A, Grumbaum E. Maternal stress, pregnancy diseases and child hyperactivity and attention deficit (ADHD). Biomed J Sci Tech Res. 2018;12(2).

47. Ronald A, Pennell CE, Andrew JO. Prenatal maternal stress associated with ADHD and autistic traits in early childhood. Front Psychol. 2010;1. doi:10.3389/fpsyg.2010.00223

48. Stephen V, Mick E. Molecular genetics of attention deficit hyperactivity disorder. Psychiatr Clin N Am. 2010;33(1):159-180. doi:10.1016/j.psc.2009.12.004

\section{Publish your work in this journal}

Psychology Research and Behavior Management is an international, peer-reviewed, open access journal focusing on the science of psychology and its application in behavior management to develop improved outcomes in the clinical, educational, sports and business arenas. Specific topics covered in the journal include: Neuroscience, memory and decision making; Behavior modification and management; Clinical applications; Business and sports performance management; Social and developmental studies; Animal studies. The manuscript management system is completely online and includes a very quick and fair peer-review system, which is all easy to use. Visit http://www. dovepress.com/testimonials.php to read real quotes from published authors. 